\title{
Truth and bias: Robust findings?
}

\author{
Bernhard Clemm von Hohenberg (EUI)
}

7 Oktober, 2020

\begin{abstract}
Differences in information processing across ideological groups have been a recurring theme in political science. The recent debate about "fake news" has brought attention to the question whether US liberals and conservatives differ in how they evaluate the truth of information. Researchers have asked, first, which side is better at discerning true from false information (truth discernment), and second, whether liberals and conservatives are driven to different degrees by the ideological congruence of information (assimilation bias). The paradigmatic designs to study these question require selecting or constructing informational stimuli. As I show empirically with two robustness tests and one extended replication of previous studies, this selection/construction necessarily affects the resulting (a)symmetries. When it is unclear how well the selection represents some universe of real-world information, we should thus be wary of results about asymmetries. Ideally, studies should find ways to randomly sample stimuli from the target population of information.
\end{abstract}

European University Institute, Via dei Roccettini 9, 50014 San Domenico di Fiesole, Italy. Email: bernhard. clemm@eui.eu. Orcid ID: 0000-0002-6976-9745. I am grateful to Hunt Allcott, Paul Bauer, Aleksandra Cichocka, David Rand, Diego Gambetta, Matthew Gentzkow, Andrew Guess, Jennifer Jerit, John Jost, Hanspeter Kriesi and Gordon Pennycook for valuable feedback. This manuscript is based on a fully reproducible RMarkdown file that contains code to replicate all graphs and analyses. 


\section{Introduction}

Differences in cognitive styles, motivational needs and moral dispositions across socio-political groups have been of interest to political science and psychology for over half a century (Adorno et al., 1950; Rokeach, 1960). A large variety of studies have examined—and led to controversial debate about-whether and how conservatives and liberals, in particular in the US, differ on traits such as cognitive rigidity (Jost et al., 2003; Kahan, 2016), overconfidence (Ortoleva and Snowberg, 2015), intelligence (Heaven et al., 2011; Carl, 2014), moral values (Altemeyer, 1996; Haidt, 2012) or political tolerance (Sniderman et al., 1989; Crawford and Pilanski, 2014).

The over-arching question in this paper is whether conservatives and liberals differently evaluate the truth of the information they receive. Ideological groups could differ, first, in their truth discernment capacity, that is, their ability to tell true from false information. This issue has become especially pertinent with the debate around "fake news" and its suspected role in the US elections 2016 (Lazer et al., 2018). Some observational studies suggest that conservatives are exposed to and disseminate more misinformation on social media (Barberá, 2018; Guess et al., 2019), but controlled studies about asymmetries in believing true and false information are ambiguous (Allcott and Gentzkow, 2017; Pennycook and Rand, 2020b).

Second, conservatives and liberals could be affected differently by the information's congruence with their ideological predispositions. This tendency-which I will refer to as assimilation bias—is well-documented as a general phenomenon (Lord et al., 1979; Gerber and Green, 1999; Kahan, 2016). According to the "asymmetry hypothesis", bias should be more prevalent among conservatives (e.g. Jost et al., 2003). The evidence is ambiguous: A recent meta study concluded 
that "bias is bipartisan" (Ditto et al., 2019b), but the discussion whether this conclusion is warranted is ongoing (Baron and Jost, 2018; Ditto et al., 2019a; Guay and Johnston, 2020).

Both concepts—assimilation bias and truth discernment—have been studied with variants of the same paradigmatic design: Researchers confront subjects with information items such as news reports that are coded as true or false, and/or as congruent with either liberal or conservative positions. They then ask participants to indicate whether they believe the information to be true or accurate. In the first variant, several items are selected as they have been published in the real world ("information selection design"). In the second variant, subjects are exposed to one of two opposite items, constructed to be identical except for the ideological position with which they are congruent ("information construction design"). Although studies using these designs typically balance the quantity of true and false, as well as conservative and liberal content, it is often unclear how the selection or construction of stimuli relates to some target population of information.

As I show in this paper, this deficiency prevents us from drawing robust conclusions about ideological asymmetries, because any (a)symmetry detected depends on the informational stimulus. I run robustness tests on three peer-reviewed studies to illustrate this issue. I select papers that (1) provide findings about ideological asymmetries; and (2) made their data and materials accessible. To check the robustness of the information selection design, I randomly exclude information items multiple times in the studies by Pennycook and Rand (2019) and by Allcott and Gentzkow (2017), and test how this affects the resulting (a)symmetry each time. This amounts to analyzing, for example, how excluding the headline "The musicians 
Beyoncé and Jay Z appeared at a rally in support of Hillary Clinton" changes results. To check the robustness of the information construction design, I replicate Crawford et al. (2013), adding a more extreme version of one the original treatments. In all three cases, it shows that had the researchers constructed or selected a different set of information items in a no less justified way, they would have found different asymmetries.

A caveat about causality: The main interest of this paper is in asymmetries between conservatives and liberals, understood as self-defined groups. This does not mean that any asymmetry found is caused by ideology. As research across the social sciences has shown, individual ideology can be explained by more deep-seated traits such as personality (Adorno et al., 1950; Altemeyer, 1996; Gerber et al., 2010), social position (Sidanius and Pratto, 2001; Jost et al., 2004) or biology (Alford et al., 2005; Settle et al., 2009). Ideologies evolve constantly, sometimes change abruptly, and it is therefore likely that the ideal-typical conservative or liberal of today is different from the past. However, the focus on self-reported ideology is important on a descriptive level insofar the academic debate about it persists (cf. Ditto et al., 2019b)

The paper proceeds as follows. Section 2 broaches the issue of truth discernment, discussing theoretical expectations about ideological asymmetries in 2.1, and summarizing direct tests in Section 2.2. In Section 2.3, I test the robustness of a recent truth-discernment study by varying its informational stimuli. I turn to assimilation bias in Section 3. In Sections 3.1 and 3.2, I discuss the literature and empirical evidence on asymmetries in assimilation bias, before again examining two relevant studies for robustness in Section 3.3. In Section 4, I provide a more substantive understanding of how inclusion/exclusion of information items affects results. 
Finally, I discuss implications of this paper in Section 5.

\section{Truth discernment}

What citizens learn and know about politics is a longstanding question in social science research (Lippmann, 1922; Schumpeter, 1942; Neuman, 1986). Differences in knowledge have mostly been studied along socio-demographic lines. If the ideology of citizens is considered, it is mostly to show that partisan commitments does influence factual knowledge, not so much how such influence differs across ideological groups (Bartels, 2002; Jerit and Barabas, 2012; Jones, 2019). What is more, a large part of scholarship has focused on static knowledge (Delli Carpini and Keeter, 1996). In contrast, the question of interest in this paper, namely how citizens evaluate the truth of factual information, is more recent. By "factual", I mean to information that refers to an objective state of the world and can be either true or false. Truth discernment is the degree to which someone believes true factual information more than false factual information.

\subsection{Expectations about asymmetries}

Expectations about asymmetries in truth discernment may be motivated by several literatures. First, if one ideological group had higher levels of political knowledge, they might also be better at telling true from false information. The literature on political knowledge provides only scarce and inconclusive evidence: For example, McClintock and Turner (1962) find higher levels of knowledge among Democrats, but Delli Carpini and Keeter (1996, p. 173) report higher levels 
of knowledge among Republicans.

A second argument might focus on the substance of misinformation. Anecdotal evidence suggests that misinformation often alludes to conspiracy theories or science denial. If these contents constituted a large part of misinformation, and certain ideological groups were more receptive to them, asymmetries would ensue. Some scholars argue that conspiratorial worldviews serve epistemic and relational needs more typically found in US conservatives (Jost et al., 2018; Douglas et al., 2017). Indeed, conservatives have been found to be more likely to endorse conspiracy theories (Garrett and Weeks, 2017; Miller et al., 2016). Similarly, conservatives have shown a higher tendency to science denial (Lewandowsky and Oberauer, 2016). This implies that conservatives are less able to distinguish truth from falsehood.

Observational studies offer insights about the consumption and diffusion of misinformation across party lines. Conservatives in the US have been found to share more false news on Twitter (Barberá, 2018) and Facebook (Guess et al., 2019), and also to more likely visit fake news websites (Guess et al., 2018). It is not exactly clear that this means they also believe falsehoods more than liberals, as sharing and believing seem to be distinct outcomes (Pennycook et al., 2019). However, it could mean that misinformation is disproportionately congruent with a conservative ideological outlook, and since ideological congruence tends to make people believe, conservatives might be less discerning. 


\subsection{Empirical tests of asymmetries}

Recent studies test asymmetries in truth discernment directly. They typically compile false headlines or news reports from fact-checking web sites and true headlines from mainstream sources. Results are mixed: While some studies find that conservatives are worse at telling false from true information (Swire et al., 2017; Allcott and Gentzkow, 2017; Ross et al., 2019; Pennycook and Rand, 2019, 2020b) other findings are more ambiguous (Surma and Oliver, 2018; Faragó et al., 2020; Pennycook and Rand, 2020a; Pennycook et al., 2020). I will refer to the design of these studies as the information selection design. While researchers mostly balance the information in terms of truth, exposing subjects an equal number of true and false headlines, theoretical justifications of how the choice was made are not always present. Thus, it remains unclear to what extent studies allow to generalize to a larger population of news.

\subsection{Robustness check of a truth discernment study}

A recent study by Pennycook and Rand (2019) tests various hypotheses, for example, to what extent truth discernment correlates with cognitive reflection. As a secondary question, the authors consider ideological asymmetries. In Study 2, they ask a sample of US subjects to rate the accuracy of twelve true and twelve false news headlines. Half of the headlines are pretested as congruent for Democrats, half of them as congruent for Republicans. ${ }^{1}$ More specifically, the Democrat-congruent items are pre-tested as equally distant from the midpoint of

\footnotetext{
${ }^{1}$ The ideological comparison in the study is between Democrats and Republicans, so I will refer to this dimension rather than liberal vs. conservative.
} 
a 5-point valence scale as Republican-congruent items. Thus, the conceptual estimand targeted by the authors can be characterized as truth discernment given an information supply perfectly balanced in terms of ideological valence, although it is unclear how representative the selection represents is of this target population.

The authors run a two-way ANOVA of individual truth discernment scores (z-scored average of belief in true minus z-scored average of belief in false news) on individual ideology and ideological valence of the information. A significant main effect of individual partisanship leads the authors to conclude that "Clinton supporters were better able to discern fake from real news across the full range of items than Trump supporters" (p. 7).

In the following, I show that this conclusion is not robust against picking a different subset of news items - while maintaining a balance between true and false, and between Republicancongruent and Democrat-congruent news. In a good part of these alternative selection scenarios, a different conclusion would have emerged. Further, I show that this is also the case if we constrain the alternative selections so that the degree of congruence of both pro-Republican and pro-Democrat items is equal. As these selections seem no less justifiable theoretically, the paper's conclusion regarding an asymmetry seems premature. It is worth emphasizing that the conclusion is only one result, next to a rich set of findings-however, one that is already being cited as evidence about ideological asymmetries (e.g. Quinn et al., 2020; Burger et al., 2020; Ruisch and Stern, 2020).

I start by replicating the study's original result. To focus on truth discernment per se (irrespective of ideological valence of the information), I first provide a simple graphic illustrating the result 
that Trump voters are worse at discerning the truth than Clinton voters in the left panel of Figure 1. It plots the average belief of headlines, grouped by individual partisanship and ideological valence of the information. One can see that truth discernment is slightly greater among Clinton voters. Testing individual truth discernment scores against partisanship with a t-test reveals that this difference is significant $(t=2.606, p=0.009)$. Alternatively, entering individual truth discernment scores into a two-by-two mixed ANOVA, as in the original paper, yields a significant main effect for ideology $(\mathrm{F}=5.281, \mathrm{p}=0.022)$.

Would these results have survived a variation of the stimulus? It is impossible to get data-for the same participants at the same period-on believing other items that might have been included in the survey. But assume the authors had used four out of the six headlines of each category, thus keeping the balance of true versus false headlines and of liberal-congruent and conservative-congruent headlines. From a conceptual point, this would have been no less justifiable since we do not know how the individual headlines were selected and how they relate to the real-world universe of news at the time of the study.

I therefore reproduced the results after repeated random sampling of four out of six headlines from each category. The right panel of Figure 1 shows the distribution of truth discernment differences between Trump voters and Clinton voters for 500 random sub-samples. Positive values mean that Trump voters are more discerning, negative values that Clinton voters are more discerning. The portion of differences that are significant according to the same t-test as reported above are shown in dark. Overall, in 55.8 percent of sub-samples, a significant difference emerges, but in 9.7 percent of these cases Trump voters are more truth-discerning. 
See the Appendix for results under different specifications, e.g. and running the original ANOVA instead of a t-test. These specifications yield the same basic result.

However, the authors' item selection was guided by ensuring that items congruent for Democrats and items congruent for Republicans are congruent to an equal degree. Thus, I next check which of the subsamples equally satisfy this criterion, using a t-test to examine whether pro-Republican and pro-Democrat headlines were on average equally distant from the scale midpoint. ${ }^{2}$ of all subsamples, a large majority of 93.8 percent satisfy this criterion. Of these, 44.8 percent yield an insignificant asymmetry estimate. Hence, this important theoretical constraint does not change my main finding.

Thus, had Pennycook and Rand (2019) chosen a slightly different set of informational stimuli, in a large number of cases they would have concluded that there was no ideological asymmetry. The Appendix also reports a robustness analysis of Study 1 in the same paper. In this case, the asymmetry does survive the sub-sampling procedure. However, as also discussed in the Appendix, the sets of items in Study 1 and Study 2 widely overlap: The authors kept some items but exchanged and added others. The fact that this made the results less robust further supports the argument that conclusions about asymmetries are vulnerable to the selection of stimuli.

\footnotetext{
${ }^{2}$ This is the procedure applied in the original research, as described by the authors in an email conversation.
} 


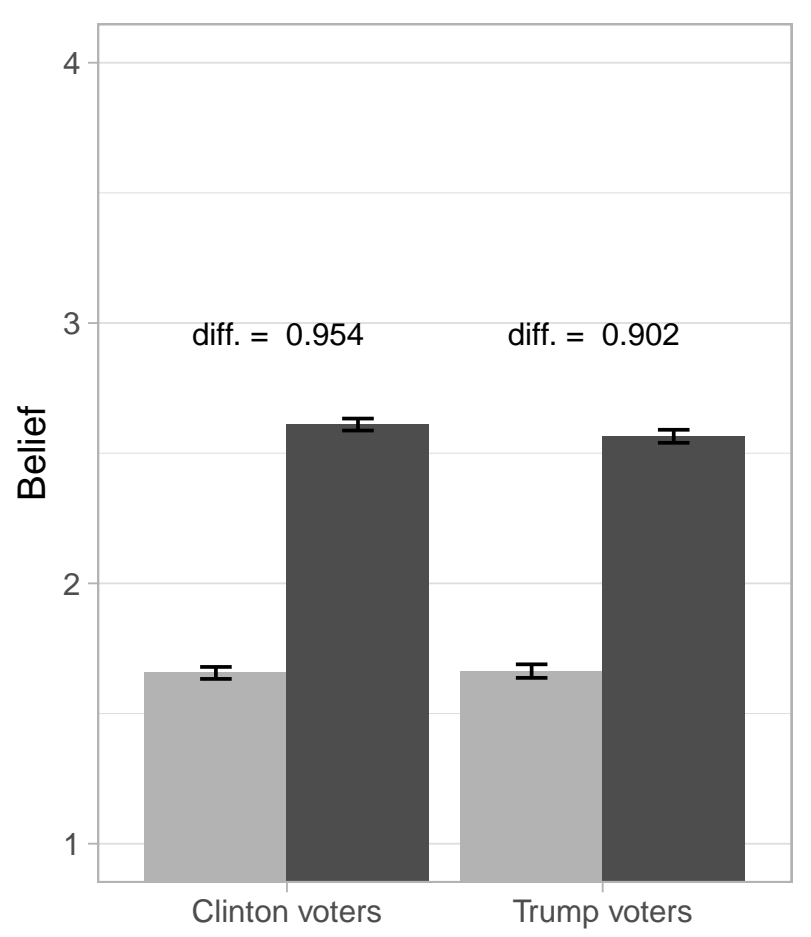

Truth False True

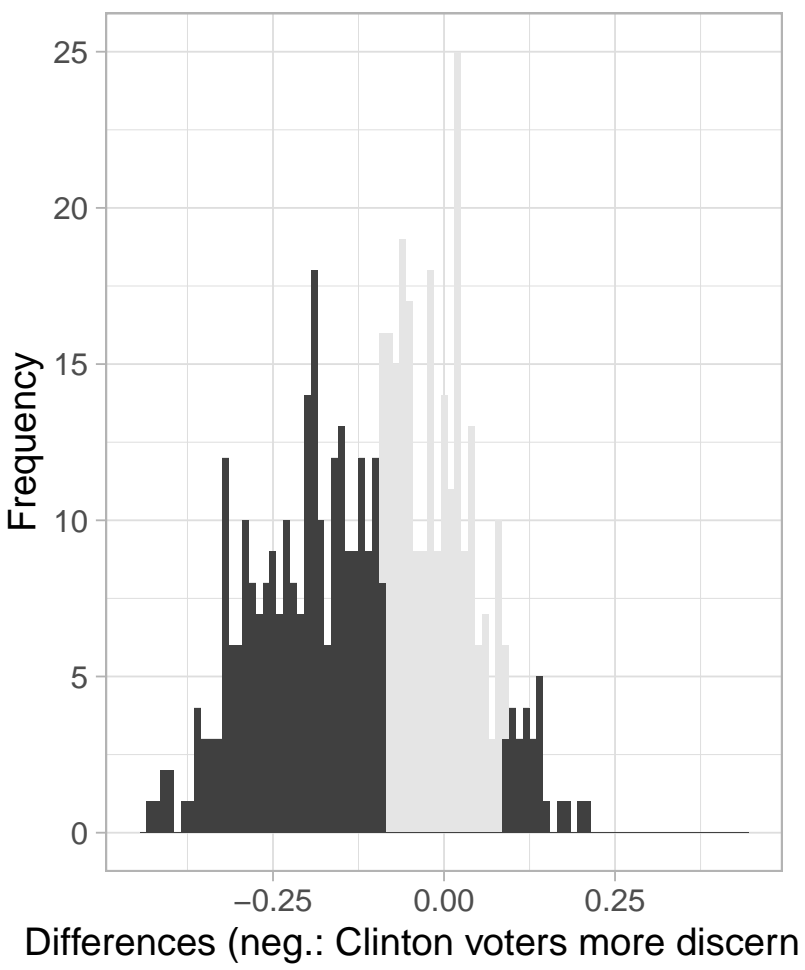

95\%-Significance

No Yes

Figure 1: Replication of Pennycook and Rand (2019)

\section{Assimilation bias}

Evidently, the truth value of information does not only determine whether people believe it. Ever since the experiments by Hastorf and Cantril (1954), and by Lord et al. (1979), it has become a staple of political science and psychology that people evaluate information more favorably when is in line with their preferred conclusions-a tendency often called assimilation bias (Houston and Fazio, 1989; Ditto and Lopez, 1992; MacCoun, 1998; Taber and Lodge, 2006; Crawford et al., 2013; Kahan et al., 2017). ${ }^{3}$ More specifically, I speak of assimilation bias

\footnotetext{
${ }^{3}$ Note that some have questioned whether the phenomenon in question should be termed "bias", as it might be explicable by rational processes alone (e.g. Gerber and Green, 1999). See further below for a brief discussion. As I am agnostic about the reasons for the phenomenon in this paper, I use the common term "assimilation bias".
} 
to describe the tendency to believe factual information more when it is congruent with one's ideological positions than when it is incongruent with one's positions. ${ }^{4}$

Note that asymmetries in truth discernment do not necessarily say anything about asymmetries in assimilation bias. If one ideological group is more discerning of the truth, that does not mean that it is less biased. At least in theory, it is possible to imagine that one group is more truth discerning and less biased, or the other way around, especially since there are many factors independent of ideology that drive believing information, such as fluency (cf. Brashier and Marsh, 2020; Schwarz et al., 2016).

\subsection{Theories about asymmetries}

There are different ideas about whether the effect of congruence on belief varies across the ideological spectrum. Proponents of the "asymmetry hypothesis" describe conservatism as "motivated social cognition" linked to several cognitive tendencies that might enhance assimilation bias (Jost et al., 2003). For example, the correlation of conservatism and dogmatism, described as the "need to ward off threatening aspects of reality" (Rokeach, 1960, p. 67) suggests that conservatives are more likely to denigrate information incongruent with their ideological commitments. A higher prevalence of a need for closure among conservatives (Webster and Kruglanski, 1994; Jost et al., 1999; Golec, 2002) bears out similar expectations, just as a higher level of threat sensitivity (Hibbing et al., 2014; Lilienfeld and Latzman, 2014) and a lower degree of cognitive reflection or analytic thinking do (Pennycook et al., 2012; lyer et al., 2012;

\footnotetext{
${ }^{4}$ Terms alternative to congruence include consonance, consistence or congeniality.
} 
but Kahan, 2013).

A different perspective holds that insofar assimilation bias is product of motivated cognition, it will occur no matter one's political position. Given the evidence for self- and group-enhancing biases across populations and societal groups (Billig and Tajfel, 1973; Kunda, 1990; Ditto, 2009; Mercier and Sperber, 2013), proponents of the "symmetry hypothesis" question that liberals are immune to this tendency and emphasize that any reasoning about politics is affected by motivational bias, even though on different issues (Graham et al., 2013; Brandt et al., 2014). Some also point out that the causal nexus between certain psychological traits and outcomes in information processing is not stringent (Nisbet et al., 2015; Guay and Johnston, 2020).

The role of rationality and cognitive sophistication in assimilation bias further complicates predictions about asymmetries. Some who interpret evidence of assimilation bias as a product of motivated reasoning argue that cognitive reflection may actually enhances bias, as it provides the mental resources to come up with reasons why uncomfortable information "cannot" be true (Kahan, 2013, 2016). In contrast, another argument suggests that the evidence related to assimilation bias in fact does not show any "bias", but can be construed in terms of rational Bayesian updating (Gerber and Green, 1999; Hill, 2017; Tappin et al., 2020b,a). In this account, disbelieving incongruent information can be explained by the large discrepancy with one's prior beliefs, believing congruent information by a closer proximity to priors. Some empirical studies find support for this claim (Tappin et al., 2018; to some extent Hill, 2017). Insofar as rationality as cognitive sophistication is indeed more prevalent in liberals, this would suggest an asymmetry in assimilation "bias". 


\subsection{Empirical tests of assimilation bias}

Two designs are commonly applied to test assimilation bias. First, the information selection design already described above: Study participants are exposed to a number of real-world news items and asked to judge their truth, a design especially prominent in recent studies motivated by the debate on "fake news". In fact, many recent studies test truth discernment and assimilation bias together, examining who is most susceptible to false information and how much belief is driven by congruence. Typically, researchers pretest a set of information in terms of ideological congruence and then balance the number of news items in terms of congruence. Recent studies using this design are inconclusive: Some studies do not find any asymmetry (Allcott and Gentzkow, 2017; Faragó et al., 2020; Pennycook and Rand, 2020a), others suggest greater assimilation bias among conservatives (Pennycook and Rand, 2020b; Arendt et al., 2019). As I show below in Section 3.3.1, the magnitude of effects depends on the chosen stimuli.

A second design, inspired by early research on information processing in psychology, constructs opposite stimuli that are identical except for their ideological congruence. In this information construction design, the information items are often motivated by an actual news reports, but are manipulated and have never been published in the real world. These studies have shown the existence of assimilation bias in many contexts and forms, but few have explicitly tested its magnitude across different ideological groups. A recent meta study by Ditto et al. (2019b) aims to uncover implicitly measured magnitudes and for this purpose reviews 51 experimental studies. Defining bias more generally as the "general tendency for people to think or act in ways 
that unwittingly favor their own political group or cast their own ideologically based beliefs in a favorable light", the study reveals that "bias is bipartisan", i.e. symmetric.

A closer look at Ditto et al. (2019b) reveals that the studies reviewed cover a diversity of psychological processes. ${ }^{5}$ A first type of process reviewed concerns the evaluation of policy proposals or arguments depending on partisan sponsorship (Druckman, 2001; Cohen, 2003; Malka and Lelkes, 2010; Bullock, 2011; Hawkins and Nosek, 2012; Smith et al., 2012; Bergan, 2012; Bolsen et al., 2014; Crawford et al., 2014; Smith, 2014; Ciuk and Yost, 2016; Mullinix, 2016). Another type could be summarized as the evaluation of moral misbehavior: Subjects typically judge contentious behavior by politicians, activists or institutions less severe when committed by "their" side (Claassen and Ensley, 2016; Christenson and Kriner, 2017; Kahan et al., 2012; Crawford and Xhambazi, 2015; Furgeson et al., 2008a,b; Kopko et al., 2011; Kahan et al., 2016). Only a part of the studies address assimilation bias as defined above, i.e. the tendency to judge the truth or methodological validity of factual information depending on its congruence (Lord et al., 1979; MacCoun and Paletz, 2009; Crawford et al., 2013; Kahan, 2013; Liu, 2013; Munro and Munro, 2014; Scurich and Shniderman, 2014; Kahan et al., 2017). ${ }^{6}$

But even if one reran the meta review just for the studies testing assimilation bias, the design would not allow us to draw any robust conclusions about ideological asymmetries. Again, the underlying reason for this deficiency is the unclear relation of the stimulus to the any universe of information. As researchers construct two information items with opposite factual content,

\footnotetext{
${ }^{5}$ See also Guay and Johnston (2020) for this observation.

${ }^{6}$ The remaining studies reviewed are harder to categorize. It is unclear what we can learn about the different phenomena by summarizing them under one umbrella. They might be driven by quite different underlying psychological traits. For example, the effect of partisan endorsement could be construed as "information shortcut" (e.g. Downs, 1957; Popkin, 1991) and therefore have a rational basis.
} 
they in effect create two different factual "worlds", and the magnitude of assimilation bias depends on the how believable subjects find each of these worlds. Replicating and extending a recent study in Section 3.3.2 will illustrate this argument empirically.

\subsection{Robustness checks: Assimilation bias}

\subsubsection{Information selection design}

To examine the robustness of conclusions about asymmetries resulting from the information selection design, I analyse a recent study by Allcott and Gentzkow (2017). The authors study drivers of people's belief in fake and true news published before the 2016 US presidential elections. They expose each subject to thirty headlines that they code as either "pro-Clinton" or "pro-Trump". Their collection of thirty headlines is built from five "categories": six false stories mentioned in mainstream media in the week before the elections ("big fake"); the six "most recent" election-related stories during the week before the election from the Guardian ("big true"); the eight top "most recent" stories classified by two the fact-checking sites Snopes and PolitiFact as unambiguously false ("small fake"); the four top "most recent" stories classified by Snopes and PolitiFact as unambiguously true ("small true"); and last, six invented fake news headlines ("placebo"). Each of these categories contains an equal number of pro-Clinton and pro-Trump headlines. Other than the online reach, the selection of news items is not theoretically motivated by the authors.

The authors regress belief in each participant-headline encounter on an interaction of being a 
Democrat and reading a pro-Clinton headline, and another interaction of being a Republican and reading a pro-Trump headline (Table 2 Column 1 in the original paper). The interaction for Republicans (0.147) is smaller than for Democrats (0.172), but this difference is not significant according to a Wald test (0.422). Further, the authors create a congruence dummy variable according to whether an individual-headline pairing is congruent or not, and regress belief on an interaction between congruence and partisanship, controlling for other covariates (Table 2 Column 3 in the original paper). Again no significant interaction emerges. The results imply ideological symmetry. ${ }^{7}$

To illustrate the original results, consider Panel A of Figure 2. It plots the average belief in proClinton headlines and the average belief in pro-Trump stories, for Democrats and Republicans respectively. The fact that both groups have a higher belief in congruent than incongruent headlines shows assimilation bias. The differences each group makes between congruent and incongruent headlines is 0.153 for Republicans and 0.185 for Democrats, but as the regression results imply, this difference is not significant. ${ }^{8}$

What would have happened had the authors chosen the sets of news items differently? I start with excluding different categories of headlines one by one, which does not change the balance of pro-Clinton and pro-Trump headlines. It shows that in two out of five exclusion cases, significant effects do appear. Without the set of "small fake" headlines, the first regression discussed above yields an interaction coefficient for Republicans that is 0.072 higher than for

\footnotetext{
${ }^{7}$ Again, it is worth emphasizing that the paper offers a rich array of results next to asymmetries in assimilation. The paper also tests asymmetries in truth discernment. Find robustness tests for these results in the Appendix.

${ }^{8}$ Similarly, if we compare individual-level assimilation bias (computed as the average belief of congruent minus average belief of incongruent headlines per individual) by group using a t-test, only a marginally significant difference emerges $(\mathrm{p}=0.076)$.
} 
Democrats (Wald test: $\mathrm{p}=0.013$ ). Without the set of "small true" headlines, the same model reveals that Democrats are more biased (difference of coefficients $=0.10, \mathrm{p}=0.013$ ). For other excluded categories, the original results hold (cf. Appendix for all results). These different selections of headlines seem no less justified: For example, without the "small fake" items, the selection is actually more balanced between true and false headlines.

To show the problem more generally, I simulate results after randomly excluding headlines 500 times. For each sub-sample, I exclude ten out of fifteen pro-Clinton and ten out of fifteen pro-Trump headlines, and estimate the same regressions as above. Panel B of Figure 2 shows the distribution of effect sizes for the first regression. Dark regions indicate significance. It shows that in 265 out of 500 sub-samples, effects sizes are significant. An even higher number of sub-samples reveal significant effects for the second regression (cf. Appendix). Hence, in many hypothetical selection scenarios, the authors would have drawn a different conclusion about asymmetries in assimilation bias.

\subsubsection{Information construction design}

I next turn to robustness of the constructed information design. The studies using this design reviewed in Ditto et al. (2019b) typically construct two information items that pertain to the same factual question (e.g. whether the death penalty discourages crime), but differ in their conclusions. Thus, stimuli are identical except for their congruence with opposite positions on some ideological dimension. Subjects are randomly assigned to one or the other version, and assimilation bias is found when there is an interactive effect of ideology and this treatment on 


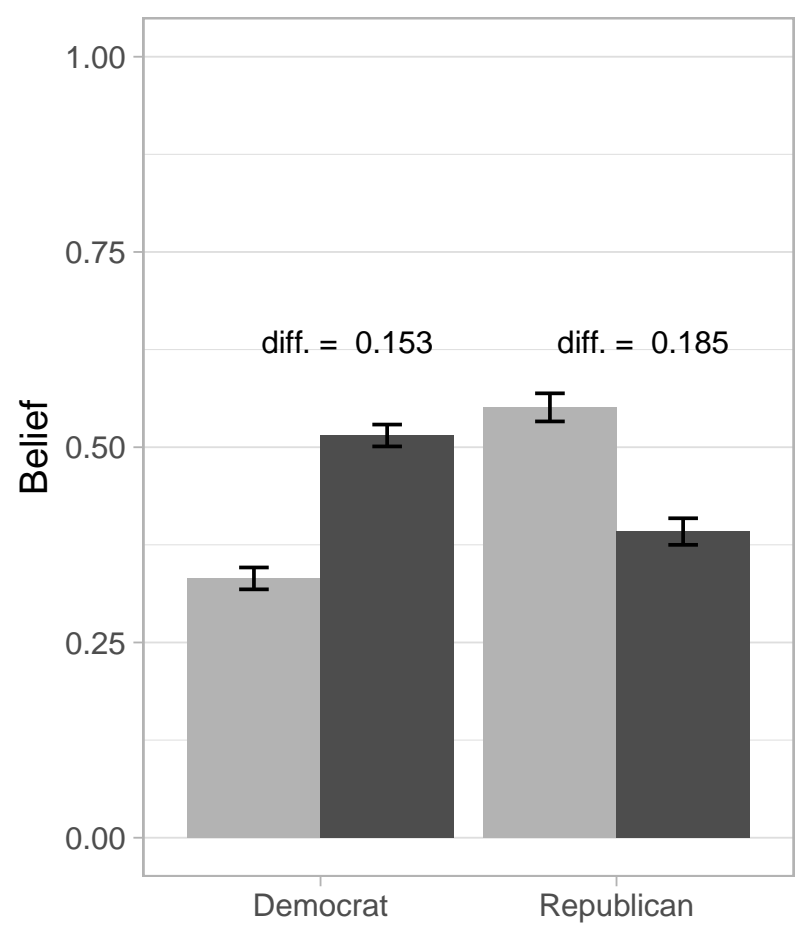

Congruence pro-Trump pro-Clinto।

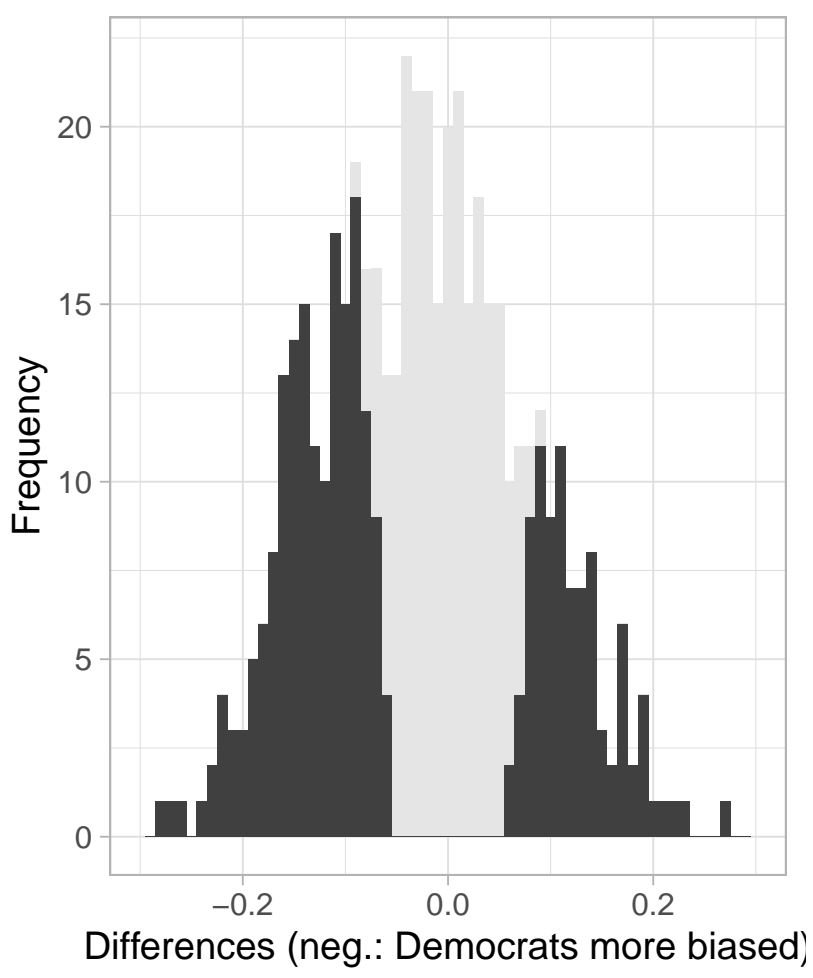

95\%-Significance
No

Figure 2: Replication of Allcott and Gentzkow (2017)

the evaluation of the information.

Take the study by Crawford et al. (2013), which asks subjects to read an article on affirmative action. One treatment reports a (real) study claiming that affirmative action policies are harmful to the success of African American students at law schools. In the other treatment, the article claims the opposite. Subjects were asked to indicate to what extent they believed the report to be true. The authors report a significant interaction between the treatment and an underlying ideological trait-in the original study, social dominance orientation (SDO). It is again worth emphasizing that the authors do not compare the magnitude of bias between subjects with high and low SDO. But one may conclude from the graph in Crawford et al. (2013, Figure 3) that 
those with high SDO are less biased than those with low SDO. Also, the meta study by Ditto et al. (2019b) uses the data to test exactly this asymmetry.

To show that this conclusion is not justified, I ran an extended replication. I recruited a US sample of 583 subjects with quotas on age, gender and state of residence through the survey company Dynata. I used a slightly shortened version of the two original articles. Crucially, I added a third treatment: In this version of the pro-affirmative-action article, the numbers made the conclusion even more compelling. For example, where the original article cited numbers suggesting that examination success rates of African-Americans were about average, the new pro-affirmative-action article cited numbers that they were even better than average and thus allowed a more extreme conclusion about the benefits of affirmative action. In sum, subjects in my replication were randomly assigned to one of three treatments: the original conservative-congruent article (anti affirmative action), the original liberal-congruent article (pro affirmative action) or a new, more extreme liberal-congruent article (pro affirmative action). The stimuli texts can be found in the Appendix.

Since I am interested in differences on the conservative-liberal dimension, I test effects across ideology, rather than SDO. The panel A of Figure 3 illustrates the replication of the original two treatments, plotting linear fits of belief on ideology by treatment. The result is similar to the original study: Liberal subjects make a much larger difference between the two reports than conservatives $^{9}$. However, once the liberal-congruent treatment is replaced by the more extreme version of my replication, bias appears on the conservative side as well-even if not as extreme

\footnotetext{
${ }^{9}$ It appears that conservatives actually believe the liberal article more, but this margin is not significant.
} 
as for liberals, as panel B of Figure 3 shows.

(A) Original treatments

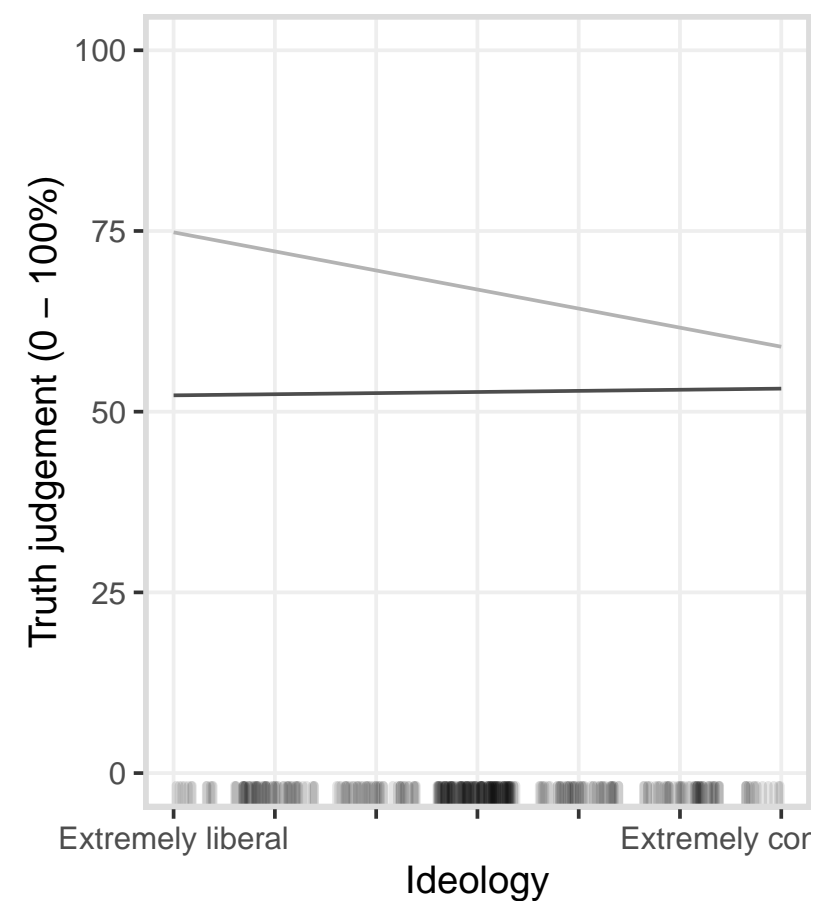

(B) New liberal treatment

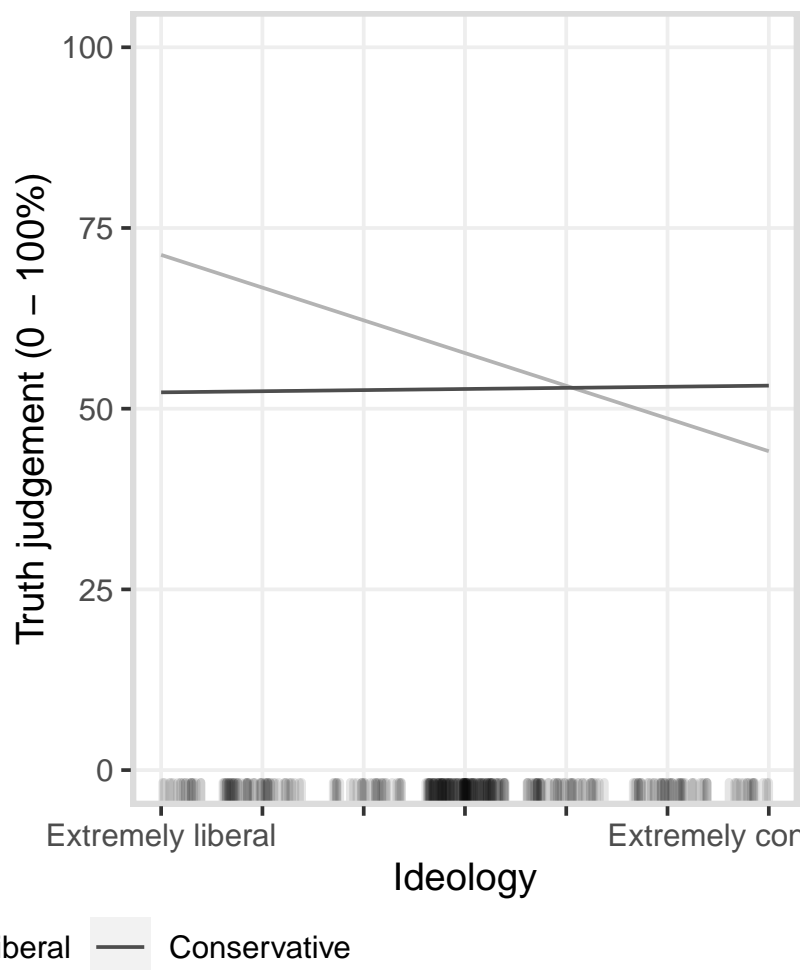

Figure 3: Replication of Crawford et al. (2013) and alternative implementation

To test whether the asymmetry is statistically significant in the original study, but not the modified version, I first construct a congruence variable on a scale from - 3 and 3 that is negative for conservatives treated with the liberal-congruent report and for liberals treated with the conservative-congruent report; and positive for the opposite cases. I then regress belief on an interaction between congruence and ideology. The results are shown in Table 1. In both the original version of the experiment and the modified version, congruent information elicits higher belief than incongruent information. In the original version, the interaction between congruence and ideology is significant in the expected direction: Liberals show greater assimilation bias. However, in the modified version, this significant effect vanishes. Hence, in this scenario one 
might conclude that bias is bipartisan.

Table 1: Extended replication of Crawford et al. (2013)

\begin{tabular}{lcc}
\hline \hline & \multicolumn{2}{c}{ Outcome: Belief } \\
\cline { 2 - 3 } & Original treatment & New treatment \\
\hline Report congruence & $5.20^{* *}$ & $3.17^{*}$ \\
& $(1.59)$ & $(1.48)$ \\
Ideology & -1.11 & $-2.15^{*}$ \\
& $(0.84)$ & $(0.83)$ \\
Congruence * Ideology & $-0.95^{* *}$ & -0.20 \\
& $(0.34)$ & $(0.33)$ \\
Constant & $64.57^{* * *}$ & $63.85^{* * *}$ \\
& $(3.62)$ & $(3.54)$ \\
\hline Observations & 362 & 355 \\
Akaike Inf. Crit. & $3,378.95$ & $3,314.92$ \\
\hline \hline Note: & ${ }^{*} \mathrm{p}<0.05 ;{ }^{* *} \mathrm{p}<0.01 ;{ }^{* * *} \mathrm{p}<0.001$ \\
\end{tabular}

This shows that the construction of treatment information can influence the magnitude of bias at different ideological positions (as in fact acknowledged in the review by Ditto et al. (2019b), see Supplementary Material). The data in the pro-affirmative action article in Crawford et al. (2013) was made up. The made-up information in my additional treatment therefore seems equally valid: Both constructed treatments lack a clear relation to ground truth and it is unclear which yields the "right" contrast between conservatives and liberals. This problem is not entirely overcome by more recent studies such as Guay and Johnston (2020), that otherwise offer important improvements to the measurement of bias. ${ }^{10}$

\footnotetext{
${ }^{10}$ Even though opposite treatments in Study 1 by Guay and Johnston (2020) are symmetric, i.e. containing identical but reversed numbers, it is still not entirely clear whether they contain the degree of congruence that produces the "right" contrast.
} 


\section{Qualitative examination of stimuli}

Concerning the validation of Pennycook and Rand (2019) and Allcott and Gentzkow (2017), what is it about certain information items that drives results? I will now identify which information items, when included or excluded, drive variation across random sub-samples. In the following analyses, the difference between conservatives and liberals (either in truth discernment or assimilation bias) is the outcome. The selection of items included in the sub-sample is the independent variable, coded as a dummy for each item. Due to collinearitywhether any headline is included in the sub-sample is determined by the knowledge about inclusion of all other headlines-a conventional regression approach is problematic. Instead, I rely on a random-forest approach, built on regression trees. A regression tree recursively partitions the data to maximize the difference on the dependent variable between the ensuing data partitions, by searching all independent variables for possible cutoffs. A random forest consists of multiple such trees built on random subsets of the data.

I first apply this technique to the 500 sub-samples built from the data by Pennycook and Rand (2019). Details on variable importance, and on the direction of impact, can be found in the Appendix. The headline that had the biggest impact ${ }^{11}$ in making Trump voters appear relatively more discerning reads "Clinton PAC aims to boost left-wing, anti-Trump groups - will she still have clout?", with a teaser "Hillary Clinton is returning to politics far from the national stage she exited in November 2016 but close to the issues she left behind - backing grassroots groups intent on thwarting". This true headline was published by foxnews.com. The headline that

\footnotetext{
${ }^{11}$ As determined by The grf package in $R$.
} 
had the biggest in making Clinton voters appear relatively more discerning is "Vladimir Putin 'personally involved' in US hack, report claims" with a teaser "Russian president made key decision in operation seen as revenge for past criticism by Hillary Clinton, says NBC". This is another true report, published by the Guardian. The most influential false headline reads "Trump to ban all TV shows that promote Gay Activity Starting with Empire as President - The \#1 Empowering Conscious Website In the World", published by colossill.com. It made Trump voters appear relatively more truth discerning.

There are several reasons why the inclusion or exclusion of these items might have mattered. First, it could be the degree to which the headlines themselves transport uncertainty. The headline about Putin says that a "report claims". This might allow Trump supporters to more easily discount it as false even though it is true. Including this headline in the study will make them appear worse at truth discernment. Second, the source might matter: If Republicans, stereotypically speaking, believe everything by Fox News, and disbelieve everything by the Guardian (and Democrats vice versa), truth discernment asymmetries will depend on the mix of sources. ${ }^{12}$ Last, we might suspect the extremity of congruence to make the difference. For example, the false headline about Trump banning TV shows, an unconstitutional act, sheds such an extremely bad light on Trump that most of his supporters will likely reject it outright. In contrast, it might be tempting for Trump opponents to entertain this idea as true. In consequence, Trump voters will appear more discerning because they rightly do not believe this headline.

Next, I run a similar analysis for the 500 sub-samples built from Allcott and Gentzkow (2017).

\footnotetext{
${ }^{12}$ Note that in another study, the authors conclude that sources matter less than content for people's truth discernment capacity (Pennycook and Rand, 2020a).
} 
The question is which headlines, when included, make Republicans or Democrats appear more biased, that is, prefer congruent over incongruent items to a greater extent. The headline that contributed most to apparently greater Republican bias is "At the 9/11 memorial ceremony, Hillary Clinton stumbled and had to be helped into a van" (true). The headline contributing most to Democrats appearing more prone to assimilation bias reads "The musicians Beyoncé and Jay Z appeared at a rally in support of Hillary Clinton" (true). Below, I plot how exclusion of these two headlines, respectively, affects belief in congruent and incongruent content by partisanship. The left panel of Figure 4 shows what happens if the 9/11 memorial-ceremony headline is excluded from the data. The average believability of pro-Trump items goes down. This makes Republicans seem more, and Democrats less biased than in the original data. In contrast, excluding the item about Beyoncé and Jay Z makes pro-Clinton items less believable on average, as shown by the right panel of Figure 4. In consequence, Democrats appear less biased, Republicans more biased.

This is where the two types of validation exercises in this paper connect. Note the similarity of Figure 4 to Figure 3, the replication of the Crawford et al. (2013) study. Somewhat counterintuitively, information congruent for one group that is also highly believable in general makes this group appear less biased. In other words, the general believability of information will influence asymmetries in assimilation bias. One reason why something is generally believable is arguably that it is a fact, or connected to other facts, generally known to people. For example, if everyone is aware of the facts congruent for liberals used in a study, but less aware of the facts congruent for conservatives, people will be more likely to believe the former than the 


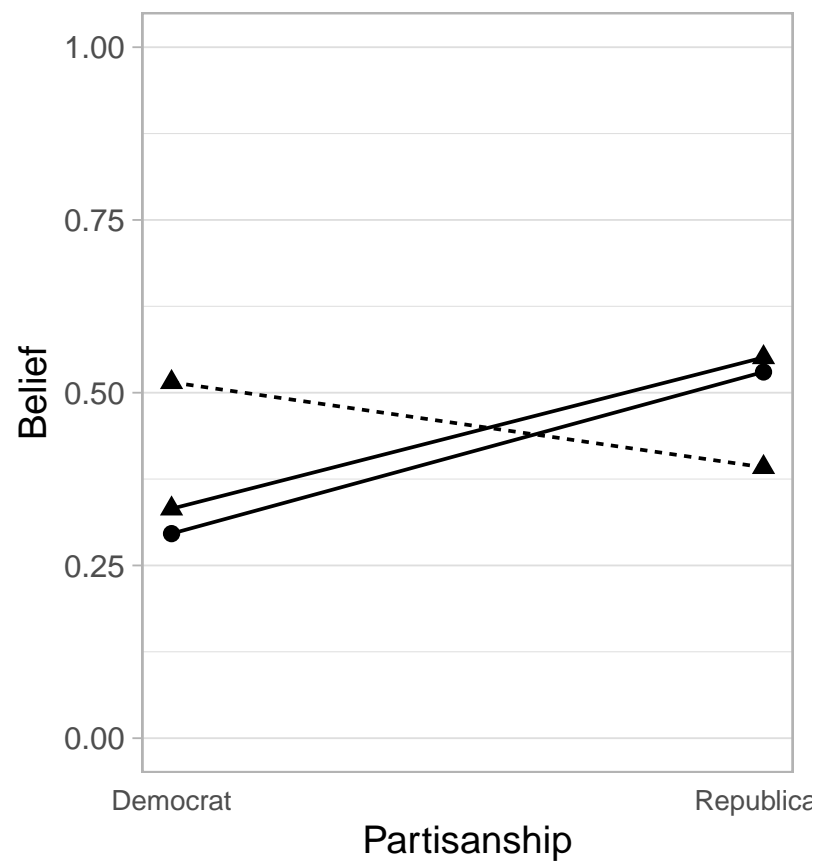

Data • '9/11 Memorial' excluded $\quad \Delta$ Complet $\epsilon$

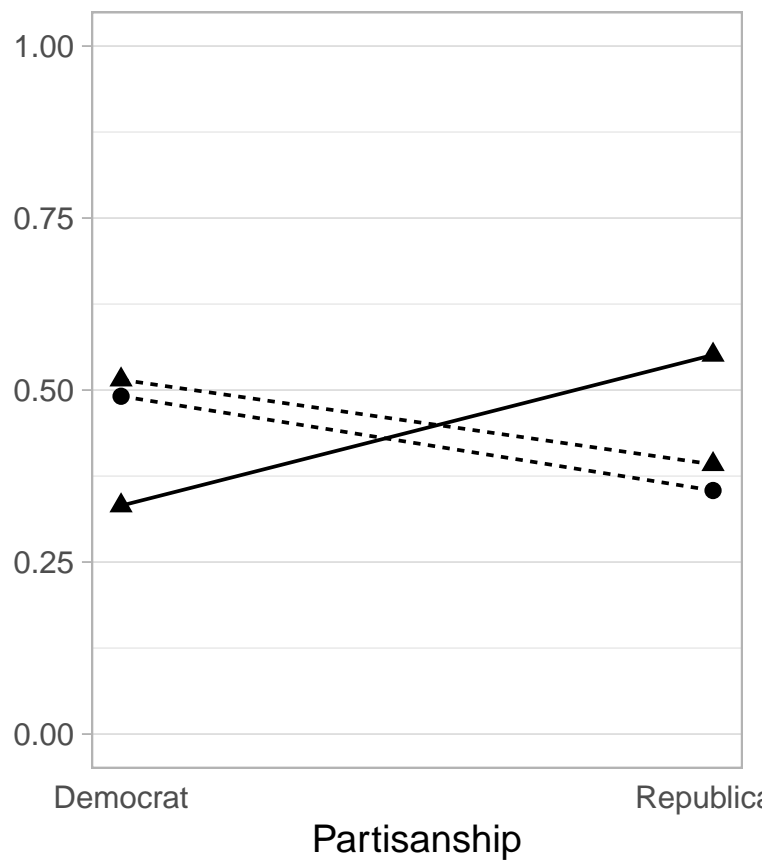

Data - 'Beyonce' excluded $\Delta$ Complete

$$
\text { Congruence - pro-Trump -... pro-Clinton }
$$

Figure 4: Exclusion of important headlines in Allcott and Gentzkow 2017

latter. In consequence, assimilation bias will appear greater among liberals. The replication of Crawford et al. (2013) can be interpreted in a similar light: The new liberal-congruent treatment represents a more extreme factual claim. This makes it less believable on average. In consequence, bias on the liberal side shrinks, and bias on the conservative side grows. The asymmetry of the original experiment—liberals seemed more biased than conservativesdisappears. 


\section{Conclusion}

I have attempted to show that the described research designs fail to robustly measure ideological asymmetries in truth discernment and assimilation bias. The issue can be seen as one of external validity, that is, the task to ensure that "conclusions can be applied across different populations or situations" (McDermott, 2011, p. 34). The research questions studied in this review-which ideological group is better at discerning true from false information? And which group as a greater tendency to be biased towards congruent information?- can be construed in terms of different "populations" and "situations" we might study: First, there is a population of people we are interested in, i.e. all self-identified conservatives and liberals in the US. Then, there is also universe of information that these people may encounter on a daily basis. Our interest lies in understanding these encounters between an individual and an information item, which are to be explained in terms of information characteristics (i.e. truth and valence) and individual characteristics (i.e. ideology).

External validity across populations is a classic problem in social-science research. Representativeness is ideally attained by drawing a random sample from the population of interest. In practice, researchers use non-probability samples and weight them on a couple of auxiliary variables such as age and gender (Berinsky, 2017). Is there are similar way to ensure external validity across "situations", e.g. make the study representative of the possible encounters between people and information? Just as we would ideally like to sample from a population of subjects, we would like to sample from a population of information. At first, this seems difficult to achieve: The sample frame of interest is difficult to define; and even if we managed, it would 
be difficult to access. Weighting information items offers no easy way out insofar we do not know the auxiliary variables that tell us whether a selection is representative.

However, two practical recommendations for researchers to enhance the external validity of their stimuli can be made. First, researchers can make an effort to build sample frames that at least approximate the population of interest. The Internet has greatly advanced possibilities to build such frames. For example, Google News collects a large corpus of news articles from a wide range of sources on a daily basis. The challenge of future studies testing for asymmetries will be to define and find and use such sample frames for information stimuli. Second, researchers can run validations similar to the one I have applied to the studies by Pennycook and Rand (2019) and Allcott and Gentzkow (2017). Randomly excluding stimuli subsets help understand whether findings are more than just an artifact of selection. As I show in the Appendix validating Study 1 in Pennycook and Rand (2019), in some cases findings do turn out robust after applying this technique.

A further implication of this paper is that it is important, independently of establishing representativeness, to be clear about the target population of information supply studied. Some have argued that in the US, at least during a certain time period, misinformation catered over-proportionally to conservatives, that is, false information on average is more congruent to conservatives (e.g. Guess et al., 2019). Imagine that in this scenario one managed to gather a representative sample of information, and asked our study participants for each item whether they believed it. Most likely, we would find that conservatives are worse at discerning the truth, as they are more tempted to believe congruent but false information. Although this would 
be a highly relevant real-world estimate, it would be hard to discern how much it was driven by the structure of information supply, and how much by different psychological mechanisms. In contrast, we could balance stimuli to have an equal degree of conservative-congruent and liberal-congruent information, just like Pennycook and Rand (2019) do, and somehow ensure that this sample was also representative. We would likely find a smaller asymmetry due to eliminating the supply effect. The question is how relevant such a target supply would be compared to real-world supply.

Finally, a caveat about the scope of my main point. Although I conclude that is desirable to make stimuli representative of some real-world population, this requirement does not invalidate research not meeting this standard. Representativeness of stimuli seems more important for studies trying to describe effect sizes across groups than for research simply testing whether an effect exists. The latter often requires careful construction of stimulus material and effortful testing whether the right variables are manipulated. Making stimuli representative might not be possible. It is certainly difficult to draw this line. But researchers should take on the challenge to look for representative stimuli-or justify why this is not necessary. 


\section{References}

Adorno, T. W., Frenkel-Brunswik, E., Levinson, D. J., and Sanford, R. N. (1950). The Authoritarian Personality. Harper, New York.

Alford, J. R., Funk, C. L., and Hibbing, J. R. (2005). Are political orientations genetically transmitted? American Political Science Review, 99(2):153-167.

Allcott, H. and Gentzkow, M. (2017). Social Media and Fake News in the 2016 Election. Journal of Economic Perspectives, 31(2):211-236.

Altemeyer, R. A. (1996). The Authoritarian Specter. Harvard University Press, Cambridge, MA. Arendt, F., Haim, M., and Beck, J. (2019). Fake News, Warnhinweise und perzipierter Wahrheitsgehalt: Zur unterschiedlichen Anfälligkeit für Falschmeldungen in Abhängigkeit von der politischen Orientierung. Publizistik, 64(2):181-204.

Barberá, P. (2018). Explaining the Spread of Misinformation on Social Media: Evidence from the 2016 U.S. Presidential Election.

Baron, J. and Jost, J. T. (2018). False Equivalence: Are Liberals and Conservatives in the U.S. Equally “Biased"? Perspectives on Psychological Science, 56(4):217-244.

Bartels, L. M. (2002). Beyond the Running Tally: Partisan Bias in Political Perceptions. Political Behavior, 24(2):117-150.

Bergan, D. E. (2012). Partisan Stereotypes and Policy Attitudes. Journal of Communication, 62(6):1102-1120.

Berinsky, A. J. (2017). Measuring Public Opinion with Surveys. Annual Review of Political Science, 20(1):309-329. 
Billig, M. and Tajfel, H. (1973). Social categorization and similarity in intergroup behaviour. European Journal of Social Psychology, 3(1):27-52.

Bolsen, T., Druckman, J. N., and Cook, F. L. (2014). The Influence of Partisan Motivated Reasoning on Public Opinion. Political Behavior, 36(2):235-262.

Brandt, M. J., Reyna, C., Chambers, J. R., Crawford, J., and Wetherell, G. (2014). The Ideological-Congruence Hypothesis: Intolerance Among Both Liberals and Conservatives. Current Directions in Psychological Science, 23(1):27-34.

Brashier, N. M. and Marsh, E. J. (2020). Judging Truth. Annual Review of Psychology, 71(1):499515.

Bullock, J. G. (2011). Elite influence on public opinion in an informed electorate. American Political Science Review, 105(3):496-515.

Burger, A. M., Pfattheicher, S., and Jauch, M. (2020). The role of motivation in the association of political ideology with cognitive performance. Cognition, 195(December 2019).

Carl, N. (2014). Verbal intelligence is correlated with socially and economically liberal beliefs. Intelligence, 44(1):142-148.

Christenson, D. P. and Kriner, D. L. (2017). Constitutional Qualms or Politics as Usual? The Factors Shaping Public Support for Unilateral Action. American Journal of Political Science, 61(2):335-349.

Ciuk, D. J. and Yost, B. A. (2016). The Effects of Issue Salience, Elite Influence, and Policy Content on Public Opinion. Political Communication, 33(2):328-345.

Claassen, R. L. and Ensley, M. J. (2016). Motivated Reasoning and Yard-Sign-Stealing Partisans: 
Mine is a Likable Rogue, Yours is a Degenerate Criminal. Political Behavior, 38(2):317-335.

Cohen, G. L. (2003). Party Over Policy: The Dominating Impact of Group Influence on Political Beliefs. Journal of Personality and Social Psychology, 85(5):808-822.

Crawford, J. T., Jussim, L., Cain, T. R., and Cohen, F. (2013). Right-wing authoritarianism and social dominance orientation differentially predict biased evaluations of media reports. Journal of Applied Social Psychology, 43(1):163-174.

Crawford, J. T. and Pilanski, J. M. (2014). Political Intolerance, Right and Left. Political Psychology, 35(6):841-851.

Crawford, J. T., Wiley, S., and Ventresco, N. (2014). Examining Americans' attitudes toward drone strikes on the eve of the 2012 Presidential Election. Analyses of Social Issues and Public Policy, 14(1):46-60.

Crawford, J. T. and Xhambazi, E. (2015). Predicting political biases against the occupy wall street and tea party movements. Political Psychology, 36(1):111-121.

Delli Carpini, M. X. and Keeter, S. (1996). What Americans know about politics and why it matters. Yale University Press, New Haven, CT.

Ditto, P. H. (2009). Passion, reason, and necessity: A quantity of processing view of motivated reasoning. In Bayne, T. and Fernandez, J., editors, Delusion, self-deception, and affective influences on belief formation, pages 23-53.

Ditto, P. H., Clark, C. J., Liu, B. S., Wojcik, S. P., Chen, E. E., Grady, R. H., Celniker, J. B., and Zinger, J. F. (2019a). Partisan Bias and Its Discontents. Perspectives on Psychological Science, 14(2):304-316. 
Ditto, P. H., Liu, B. S., Clark, C. J., Wojcik, S. P., Chen, E. E., Grady, R. H., Celniker, J. B., and Zinger, J. F. (2019b). At Least Bias Is Bipartisan: A Meta-Analytic Comparison of Partisan Bias in Liberals and Conservatives. Perspectives on Psychological Science, 14(2):273-291.

Ditto, P. H. and Lopez, D. F. (1992). Motivated Skepticism: Use of Differential Decision Criteria for Preferred and Nonpreferred Conclusions. Journal of Personality and Social Psychology, 63(4):568-584.

Douglas, K. M., Sutton, R. M., and Cichocka, A. (2017). The psychology of conspiracy theories. Current Directions in Psychological Science, 26(6):538-542.

Downs, A. (1957). An Economic Theory of Democracy. HarperCollins, New York, NY.

Druckman, J. N. (2001). Using Credible Advice to Overcome Framing Effects. Journal of Law, Economics, and Organization, 17(1):62-82.

Faragó, L., Kende, A., and Krekó, P. (2020). We only Believe in News That We Doctored Ourselves: The Connection between Partisanship and Political Fake News. Social Psychology, 51(2):77-90.

Furgeson, J. R., Babcock, L., and Shane, P. M. (2008a). Behind the mask of method: Political orientation and constitutional interpretive preferences. Law and Human Behavior, 32(6):502510.

Furgeson, J. R., Babcock, L., and Shane, P. M. (2008b). Do a Law's Policy Implications Affect Beliefs about Its Constitutionality? An Experimental Test. Law and Human Behavior, 32(3):219-227.

Garrett, R. K. and Weeks, B. E. (2017). Epistemic beliefs' role in promoting misperceptions and 
conspiracist ideation. PLoS ONE, 12(9):1-17.

Gerber, A. and Green, D. (1999). Misperceptions about perceptual bias. Annual Review of Political Science, 2:189-210.

Gerber, A. S., Huber, G. A., Doherty, D., Dowling, C. M., and Ha, S. E. (2010). Personality and political attitudes: Relationships across issue domains and political contexts. American Political Science Review, 104(1):111-133.

Golec, A. (2002). Need for cognitive closure and political conservatism: Studies on the nature of the relationship. Polish Psychological Bulletin, 33(4):5-12.

Graham, J., Haidt, J., Koleva, S., Motyl, M., Iyer, R., Wojcik, S. P., and Ditto, P. H. (2013). Moral foundations theory: The pragmatic validity of moral pluralism. In Devine, P. and Plant, A., editors, Advances in Experimental Social Psychology. Academic Press, San Diego, CA.

Guay, B. and Johnston, C. (2020). Ideological Asymmetries and the Determinants of Politically Motivated Reasoning.

Guess, A., Nagler, J., and Tucker, J. (2019). Less than you think: Prevalence and predictors of fake news dissemination on Facebook. Science Advances, 32(2):1-9.

Guess, A., Nyhan, B., and Reifler, J. (2018). Selective Exposure to Misinformation: Evidence from the consumption of fake news during the 2016 U.S. presidential campaign.

Haidt, J. (2012). The Righteous Mind. Why Good People are Divided on Politics and Religion. Vintage.

Hastorf, A. H. and Cantril, H. (1954). They saw a game; a case study. Journal of Abnormal and Social Psychology, 49(1):129-134. 
Hawkins, C. B. and Nosek, B. A. (2012). Motivated Independence? Implicit Party Identity Predicts Political Judgments Among Self-Proclaimed Independents. Personality and Social Psychology Bulletin, 38(11):1437-1452.

Heaven, P. C., Ciarrochi, J., and Leeson, P. (2011). Cognitive ability, right-wing authoritarianism, and social dominance orientation: A five-year longitudinal study amongst adolescents. Intelligence, 39(1):15-21.

Hibbing, J. R., Smith, K. B., Alford, J. R., Hibbing, J. R., Smith, K. B., and Alford, J. R. (2014). Differences in negativity bias underlie variations in political ideology. Behavioral and Brain Sciences, 37:297-350.

Hill, S. J. (2017). Learning Together Slowly: Bayesian Updating About Political Facts. The Journal of Politics, 79(4):1403-1418.

Houston, D. A. and Fazio, R. H. (1989). Biased Processing as a Function of Attitude Accessibility. Social Cognition, 7(1):51-66.

Iyer, R., Koleva, S., Graham, J., Ditto, P., and Haidt, J. (2012). Understanding libertarian morality: The psychological dispositions of self-identified libertarians. PLoS ONE, 7(8):1-23. Jerit, J. and Barabas, J. (2012). Partisan Perceptual Bias and the Information Environment. The Journal of Politics, 74(3):672-684.

Jones, P. E. (2019). Partisanship, Political Awareness, and Retrospective Evaluations, 1956-2016. Political Behavior.

Jost, J. T., Banaji, M. R., and Nosek, B. A. (2004). A decade of system justification theory: Accumulated evidence of conscious and unconscious bolstering of the status quo. Political 
Psychology, 25(6):881-919.

Jost, J. T., Glaser, J., Kruglanski, A. W., and Sulloway, F. J. (2003). Political conservatism as motivated social cognition. Psychological Bulletin, 129(3):339-375.

Jost, J. T., Kruglanski, A. W., and Simon., L. (1999). Effects of epistemic motivation on conservatism, intolerance, and other system justifying attitudes. In Levine, J. M., Thompson, L. L., and Messick, D. M., editors, Shared cognition in organizations: The management of knowledge, pages 91-116. Psychology Press.

Jost, J. T., van der Linden, S., Panagopoulos, C., and Hardin, C. D. (2018). Ideological asymmetries in conformity, desire for shared reality, and the spread of misinformation. Current Opinion in Psychology, 23:77-83.

Kahan, D. M. (2013). Ideology, motivated reasoning, and cognitive reflection. Judgment and Decision Making, 8(4):407-424.

Kahan, D. M. (2016). The Politically Motivated Reasoning Paradigm, Part 2: Unanswered Questions. In Scott, R. and Kosslyn, S., editors, Emerging Trends in the Social and Behavioral Sciences. John Wiley \& Sons, Inc., New York, NY.

Kahan, D. M., Hoffman, D., Evans, D., Devins, N., Lucci, E., and Cheng, K. (2016). “Ideology” Or "Situation Sense"? An Experimental Investigation Of Motivated Reasoning And Professional Judgment. University of Pennsylvania Law Review, 164.

Kahan, D. M., Hoffman, D. A., Braman, D., Evans, D., and Rachlinski, J. J. (2012). "They saw a protest": Cognitive illiberalism and the speech- conduct distinction. Stanford Law Review, 64(4):851-906. 
Kahan, D. M., Peters, E., Dawson, E. C., and Slovic, P. (2017). Motivated Numeracy and Enlightened Self-Government. Behavioural Public Policy, 1(1):54-86.

Kopko, K. C., Bryner, S. M. K., Budziak, J., Devine, C. J., and Nawara, S. P. (2011). In the Eye of the Beholder? Motivated Reasoning in Disputed Elections. Political Behavior, 33(2):271-290.

Kunda, Z. (1990). The Case for Motivated Reasoning. Psychological Bulletin, 108(3):480-498.

Lazer, D. M. J., Baum, M. A., Benkler, Y., Berinsky, A. J., Greenhill, K. M., Menczer, F., Metzger, M. J., Nyhan, B., Pennycook, G., Rothschild, D., Schudson, M., Sloman, S. A., Sunstein, C. R., Thorson, E. A., Watts, D. J., and Zittrain, J. L. (2018). The science of fake news. Science, 359(6380):1094-1096.

Lewandowsky, S. and Oberauer, K. (2016). Motivated Rejection of Science. Current Directions in Psychological Science, 25(4):217-222.

Lilienfeld, S. O. and Latzman, R. D. (2014). Threat bias, not negativity bias, underpins differences in political ideology. Behavioral and Brain Sciences, 37(3):318-319.

Lippmann, W. (1922). Public Opinion. Martino Publishing, Mansfield Centre, CT.

Liu, B. S. (2013). The expertise paradox: Examining the role of different aspects of expertise in biased evaluation of scientific information. $\mathrm{PhD}$ thesis.

Lord, C. G., Ross, L., and Lepper, M. R. (1979). Biased Assimilation and Attitude Polarization: The Effects of Prior Theories on Subsequently Considered Evidence. Journal of Personality and Social Psychology, 37(11):2089-2109.

MacCoun, R. and Paletz, S. (2009). Citizens' Perceptions of Ideological Bias in Policy Research. Political Psychology, 30(1):43-65. 
MacCoun, R. J. (1998). Biases in the interpretation and use of research results. Annual Review of Psychology, 49(1):259-287.

Malka, A. and Lelkes, Y. (2010). More than Ideology: Conservative-Liberal Identity and Receptivity to Political Cues. Social Justice Research, 23(2):156-188.

McClintock, C. G. and Turner, H. A. (1962). The Impact of College upon Political Knowledge, Participation, and Values. Human Relations, 15(2):163-176.

McDermott, R. (2011). Internal and External Validity. In Druckman, J. N., Green, D. P., Kuklinski, J. H., and Lupia, A., editors, Cambridge Handbook of Experimental Political Science, pages 148-149. Cambridge University Press, Cambridge.

Mercier, H. and Sperber, D. (2013). Why do humans reason? Arguments for an argumentative theory. Behavioral and Brain Sciences, 34(2):57-74.

Miller, J. M., Saunders, K. L., and Farhart, C. E. (2016). Conspiracy Endorsement as Motivated Reasoning: The Moderating Roles of Political Knowledge and Trust. American Journal of Political Science, 60(4):824-844.

Mullinix, K. J. (2016). Partisanship and Preference Formation: Competing Motivations, Elite Polarization, and Issue Importance. Political Behavior, 38(2):383-411.

Munro, G. D. and Munro, C. A. (2014). "Soft” Versus "Hard” Psychological Science: Biased Evaluations of Scientific Evidence That Threatens or Supports a Strongly Held Political Identity. Basic and Applied Social Psychology, 36(6):533-543.

Neuman, W. R. (1986). The paradox of mass politics: Knowledge and opinion in the American electorate. Harvard University Press, Cambridge, MA. 
Nisbet, E. C., Cooper, K. E., and Garrett, R. K. (2015). The Partisan Brain: How Dissonant Science Messages Lead Conservatives and Liberals to (Dis)Trust Science. The ANNALS of the American Academy of Political and Social Science, 658(1):36-66.

Ortoleva, P. and Snowberg, E. (2015). Overconfidence in political behavior. American Economic Review, 105(2):504-535.

Pennycook, G., Cheyne, J. A., Seli, P., Koehler, D. J., and Fugelsang, J. A. (2012). Analytic cognitive style predicts religious and paranormal belief. Cognition, 123(3):335-346.

Pennycook, G., Epstein, Z., Mosleh, M., Arechar, A. A., Eckles, D., and Rand, D. G. (2019). Understanding and reducing the spread of misinformation online.

Pennycook, G., Mcphetres, J., Zhang, Y., and Rand, D. G. (2020). Fighting COVID-19 misinformation on social media : Experimental evidence for a scalable accuracy nudge intervention.

Pennycook, G. and Rand, D. G. (2019). Lazy, not biased: Susceptibility to partisan fake news is better explained by lack of reasoning than by motivated reasoning. Cognition, 188:39-50.

Pennycook, G. and Rand, D. G. (2020a). The Implied Truth Effect: Attaching Warnings to a Subset of Fake News Headlines Increases Perceived Accuracy of Headlines Without Warnings. Management Science, Articles i.

Pennycook, G. and Rand, D. G. (2020b). Who falls for fake news? The roles of bullshit receptivity, overclaiming, familiarity, and analytic thinking. Journal of Personality, 88(2):185-200.

Popkin, S. L. (1991). The reasoning voter: communication and persuasion in presidential campaigns. University of Chicago Press, Chicago.

Quinn, K. A., Bellovary, A. K., and Cole, C. E. (2020). The Tribe Has Spoken: Evidence for the 
Impact of Tribal Differences in Social Science Is Equivocal.

Rokeach, M. (1960). The open and closed mind. Basic Books, New York.

Ross, R. M., Rand, D. G., and Pennycook, G. (2019). Beyond "fake news": The role of analytic thinking in the detection of inaccuracy and partisan bias in news headlines Robert.

Ruisch, B. and Stern, C. (2020). The Confident Conservative: Ideological Differences in Judgment and Decision-Making Confidence.

Schumpeter, J. (1942). Capitalism, socialism, and democracy. Harper Perennial Modern Classics.

Schwarz, N., Newman, E., and Leach, W. (2016). Making the truth stick \& the myths fade: Lessons from cognitive psychology. Behavioral Science \& Policy, 2(1):85-95.

Scurich, N. and Shniderman, A. (2014). The selective allure of neuroscientific explanations. PLOS ONE, 9(9):1-6.

Settle, J. E., Dawes, C. T., and Fowler, J. H. (2009). The heritability of partisan attachment. Political Research Quarterly, 62(3):601-613.

Sidanius, J. and Pratto, F. (2001). Social dominance: An intergroup theory of social hierarchy and oppression. Cambridge University Press, Cambridge.

Smith, B. K. (2014). Cross-Cutting Concerns: The Varying Effects of Partisan Cues in the Context of Social Networks. PhD thesis.

Smith, C. T., Ratliff, K. A., and Nosek, B. A. (2012). Rapid Assimilation: Automatically Integrating New Information with Existing Beliefs. Social Cognition, 30(2):199-219.

Sniderman, P. M., Tetlock, P. E., Glaser, J. M., Green, D. P., and Hout, M. (1989). Principled Tolerance and The American Mass Public. British Journal of Political Science, 19(1):25-45. 
Surma, K. and Oliver, E. (2018). Believe It or Not? Credulity, Skepticism, and Misinformation in the American Public.

Swire, B., Berinsky, A. J., Lewandowsky, S., and Ecker, U. K. (2017). Processing political misinformation: Comprehending the trump phenomenon. Royal Society Open Science, 4:160802.

Taber, C. S. and Lodge, M. (2006). Motivated Skepticism in the Evaluation of Political Beliefs. American Journal of Political Science, 50(3):157-184.

Tappin, B. M., Pennycook, G., and Rand, D. G. (2018). Rethinking the link between cognitive sophistication and identity-protective bias in political belief formation.

Tappin, B. M., Pennycook, G., and Rand, D. G. (2020a). Bayesian or biased? Analytic thinking and political belief updating.

Tappin, B. M., Pennycook, G., and Rand, D. G. (2020b). Thinking clearly about causal inferences of politically motivated reasoning: why paradigmatic study designs often undermine causal inference. Current Opinion in Behavioral Sciences, 34:81-87.

Webster, D. M. and Kruglanski, A. W. (1994). Individual Differences in Need for Cognitive Closure. Personality Processes and Individual Differences, 67(6):1049-1062. 